\title{
Left Thigh
}

National Cancer Institute

\section{Source}

National Cancer Institute. Left Thigh. NCI Thesaurus. Code C105632.

A part of the lower limb, located between the hip and the knee and located on the left side of the body. 